\title{
National TB Elimination Program in Uttar Pradesh, India: A Case Study of a Country Within the Country
}

\author{
Arohi Chauhan ${ }^{1 *}$, Yogesh Patel $^{2}$ and Sandeep Chauhan ${ }^{3}$ \\ ${ }^{1}$ Research Scientist, Public Health Foundation of India, New Delhi, India \\ ${ }^{2}$ Program Director, World Health Partners, New Delhi, India \\ ${ }^{3}$ National Consultant DR TB, WHO NTEP Technical support network, New Delhi, India \\ *Corresponding author: Arohi Chauhan, C 1847 Ground Floor, Sushant lok 1 sector 43 Gurgaon 122002, Haryana, India
}

\section{ARTICLE INFO}

Received: 幽 September 16, 2021

Published: 催 September 29, 2021

Citation: Nira M Al-Munawar, Sudadi, Bhirowo Yudo Pratomo, Ardyan Wardhana. National TB Elimination Program in Uttar Pradesh, India: A Case Study of a Country Within the Country. Biomed J Sci \& Tech Res 39(1)-2021. BJSTR. MS.ID.006246.

Keyword: Tuberculosis; Uttar Pradesh; National TB Elimination Program; Drug-resistant Tuberculosis; Notification

Abbreviations: TB: Tuberculosis; RNTCP: Revised National TB Control Programme; NTP: National TB control Programme; TU: Tuberculosis Units; STC: State TB Cell, HIV: Human Immunodeficiency Virus; STCC: State TB-HIV Coordination Committee

\begin{abstract}
Tuberculosis (TB) has been the leading global cause of death from a single infectious agent, ranking above HIV/AIDS. Worldwide, 10.0 million people contracted TB in 2019, out of which 2.6 million were estimated to have occurred in India. Despite being a curable disease, every year 1.5 million people die of TB in India. India's TB efforts are flattened by the irrational use of first- and second-line anti-TB drugs, unregulated private health care, rising prevalence of TB co-morbidities, drug resistant TB and COVID-19 pandemic. The national TB program was revamped and renamed as National TB Elimination Program in 2020. The highest number of the TB cases are reported from the state of Uttar Pradesh (UP). UP has many challenges to manage the TB program with 75 districts and 18 divisions. This case study was done to review the existing situation of TB in UP and the innovations undertaken considering the fact that it contributes to $20 \%$ of the total drug sensitive TB cases in India. The results of the case study reveals that the usual notion of UP being a nonperforming state is gradually changing.
\end{abstract}

This is reflected in the efforts put by the NTEP-UP and the achievements attained so far be it in terms of active case finding of TB cases, increase in private sector notification, using Indian postal service to improved sputum specimen transportation, mobile medical van facilities in hard-to-reach area and better monitoring of the program in the state. Given the vast population and the geographical area, UP was the first state in India to establish the Regional TB Programme Management Units (RTPMU) for better monitoring and supervision of the TB program in state. The RTPMUs established shows the decentralization efforts of the state linking each district to a particular RTPMU and increasing the accountability for TB. Still, a more focused approach is required for each and every component of the TB program in UP. as a slight change in TB situation in UP will have a huge impact on the nation's TB status and thus will pave way for eliminating TB from India by 2025.

\section{Background}

\section{Prevailing Situation of Tuberculosis in India}

Tuberculosis (TB) is the world's most deadly infectious disease; it claims more than a million lives each year and affects a million more. It is the leading cause of death from a single infectious agent ranking above HIV/AIDS [1]. The global TB situation is dire with TB causing a significant mortality and morbidity [1]. India is the second-most populous country in the world with one fourth of the global incident TB cases occurring in India annually [2]. In 2019, out of the estimated global annual incidence of 10.0 million TB cases, 2.6 million were estimated to have occurred in India [1]. TB is a major public health problem in India, and it has a huge impact on the health and economy of the country [3]. Despite of the fact that TB is a curable disease if there is timely diagnosis and initiation 
of treatment, around two million people develop TB and 1.5 million die of TB in India every year.1 Poor primary health care and infrastructure in rural areas, irrational use of first- and second-line anti-TB drugs, unregulated private health care, rising prevalence of HIV TB comorbidity, widespread malnutrition fueled by poverty are some of the major challenges to control TB in India [4]. In addition, COVID-19 pandemic threatens to impact the progress made so far in reducing the burden of $\mathrm{TB}$ disease posing a considerable challenge for TB control efforts in India [1].

\section{Journey of TB}

The journey of TB control in India started with the establishment of sanatoria [5]. This was a maiden attempt in controlling the transmission of infection disease provided a timely diagnosis and initiation of treatment. Around two million people develop TB and 1.5 million die of TB in India every year [1]. The saga of TB control in India spans many decades. It is the most ancient disease with its description available in the ancient Vedas [6]. The evolution of the disease has been need-based, relating to problems of a technical, operational and managerial nature that arose over a period of time in the country [7]. As with most other countries, the initial antiTB measures implemented in India were unplanned and ad hoc in nature, confined mainly to the establishment of hospitals and sanatoria [8]. This was due partly to lack of resources and partly to a preoccupation by way of isolation. Simultaneously, around the time India gained independence, effective drugs against TB began to be available (Streptomycin 1944, PAS 1946, Thiacetazone 1950, Isoniazid 1952 and Rifampicin1966) [8].

An estimated 4000 clinics and 5,00,000 beds were required for TB control according to western standards of the time in India [9]. Owing to money restrains, attention was directed to prevention of TB by way of BCG vaccination. Along with BCG vaccination, chest radiography, sputum microscopy for case finding, and ambulatory domiciliary chemotherapy for treatment were the other available tools for the control of TB. In order to apply these tools on a large scale, genesis of National TB control Programme (NTP) happened [9]. Now despite of the existence of NTP since 1962, no appreciable change was observed in the epidemiological situation of TB in the country. The situation was further threatened with the emergence of the HIV-AIDS epidemic and the spread of multi-drug resistance TB.7 In view of this, in 1992, came the Revised National TB Control Programme (RNTCP) which was renamed as National TB Elimination Program (NTEP) in 2020 [8,10].

\section{National TB Elimination Program (NTEP)}

To revitalize the TB control programme in India, NTEP adopted the internationally recommended Directly Observed Treatment Short-course (DOTS) strategy, as the most systematic and costeffective approach [8]. It started with as a pilot in 1993 and was launched countrywide as a national programme in 1997. Rapid expansion of NTEP began in late 1998. Thirty percent of the country's population was covered by the end of 2000 , and by the end of 2002, 50\% of the country's population was covered under the NTEP. By December 2005, around 97\% (about 1080 million) of the population had been covered, and the entire country was covered under DOTS by 24th March 2006 [11]. NTEP was set in motion in Uttar Pradesh (UP) way back in 2006 when in other state it was already attaining maturity [12]. UP being the most populous and vast state in the country contributes to the highest number of TB cases. It is the vastest state in India in terms of demography as well as geography making it challenging to manage the program with 75 districts [13]. UP contributes to $20 \%$ of the total notified TB cases in India [2]. Hence, it was decided to review the existing situation of TB in UP and new innovations undertaken to combat TB in UP.

\section{Methodology}

Uttar Pradesh is bounded by Nepal on the North, Himachal Pradesh on the north-west, Haryana on the west, Rajasthan on the southwest, Madhya Pradesh on the south and south- west and Bihar on the east. Situated between 23o 52'N and 31o $28 \mathrm{~N}$ latitudes and 77o $3^{\prime}$ and 840 39'E longitudes, this is the fourth largest state in the country [14]. Uttar Pradesh is the densely populous state in the country accounting for 16.4 per cent of the country's population. It is also the fourth largest state in geographical area covering 9.0 per cent of the country's geographical area, encompassing 2, 94,411 square kilometers and comprising of 75 districts, 18 divisions, 901 development blocks and 200 million inhabited villages. The density of population in the state is 829 person per square kilometers as against 382 for the country [15]. This case study analyzes the current situation of the NTEP in UP. New initiatives were studied to understand their potential. The case study is based on the analysis of secondary data from the management information systems of the national, state and district levels. Information regarding health infrastructure and human resources was collected from Annual TB report, 2021. Data and information were also obtained from official website of the TBC-India.

\section{Current Scenario}

\section{Infrastructure}

In NTEP infrastructure, UP is headed by State TB cell (STC) located at Lucknow. The State TB Training and Demonstration Centre (STDC) is situated at Agra. STDC was built to effectively monitor and supervise the program. It is a premier institute in the state to impart quality training and workshops to all the key managers and supervisors in the state. The state has established five Regional TB programmatic Monitoring Units (RTPMUs) for better programmatic monitoring [12]. The state has 75 District Tuberculosis Centers (DTC), 993 Tuberculosis units (TU) and 
2063 Designated Microscopy Centers (DMC) [2]. In laboratory infrastructure, there are 11 Culture \& Drug Susceptibility Testing (C \& DST) laboratories out of which 5 are having LPA facility, including 2 Intermediate Reference Laboratory (IRL) and 148 CBNAAT/ TrueNAT sites are operational in the state [2]. A total of 23 DR-TB centers have been established for the management of DR-TB [2].

\section{Case Finding}

Since the programme Implementation in 2006, the state has seen noticeable achievement in improving the prevailing situation of TB and thus contributing to the achievement of Millennium Development Goal [12]. UP being the most populous and vast state in the country, it contributes to the highest number of TB cases, and it has made significant efforts in achieving these targets. The New Smear Positive case detection rate in the year 2007 which was the initial phase of implementation of NTEP in UP was 99606 per lakh population [12]. The Annual Case Notification Rate achieved in the year 2020 against target was 61\% [2]. Although the state is struggling to achieve the expected rate of more than $70 \%$, the improvement in terms of number is worth noticing. The treatment success rate of UP of 2019 cohort was $83 \%$ as compared to the national average of $82 \%$. In the present study, Presumptive TB examination rate (erstwhile Suspect examination rate) and case notification rate (CNR) were examined for the past 10 years.

Presumptive TB examination refers to a person with any of the symptoms and signs suggestive of TB including cough for more than two weeks, significant weight loss, hemoptysis, any abnormality in chest radiograph [16]. As seen from Table 1, Presumptive TB examination per lakh population has increased which relates to a more robust and strengthened case finding activities. Presumptive TB examination rate is the number of presumptive TB cases who have undergone sputum examination per lakh population per year while case notification rate is the number of tuberculosis cases registered in a specified time period (per year) in unit population (per lakh) in a defined area (e.g., TU/district/state) [16]. This depends on the extent to which patients utilize the health services. CNR is remaining steady/decreasing which denotes that even though case finding efforts are accelerated (which is reflected from Presumptive TB examination over the years), case load remains unaffected which is also one of the achievements of NTEP-UP (Tables $1 \&$ 2).

Table 1: Key indicators of case finding activities of NTEP - UP.

\begin{tabular}{|c|c|c|c|c|c|c|}
\hline Year & $\begin{array}{l}\text { Populatio n (in } \\
\text { lakh) covered by } \\
\text { NTEP UP }\end{array}$ & $\begin{array}{c}\text { Presumptive TB } \\
\text { Case Examination } \\
\text { Rate }\end{array}$ & $\begin{array}{l}\text { Annual Total Case } \\
\text { Notification Rate } \\
\text { Public Sector }\end{array}$ & $\begin{array}{l}\text { Annual Total Case } \\
\text { Notification Rate } \\
\text { Private Sector }\end{array}$ & $\begin{array}{c}\text { Annual Total Case } \\
\text { Notification Rate } \\
\text { Total }\end{array}$ & $\begin{array}{c}\text { Proportionate } \\
\text { contribution of The } \\
\text { state in National } \\
\text { Annual Case } \\
\text { notification }(\%)\end{array}$ \\
\hline 2011 & 1996 & 636 & $\mathrm{NA}^{* *}$ & $\mathrm{NA}^{* *}$ & $\begin{array}{c}143 \\
-285884\end{array}$ & $18.80 \%$ \\
\hline 2012 & 2035 & 592 & $\mathrm{NA}^{* *}$ & $\mathrm{NA}^{* *}$ & $134(27178)$ & $18.50 \%$ \\
\hline 2013 & 2055 & 604 & $\begin{array}{c}123.7 \\
-25611\end{array}$ & $0.3(622)$ & $\begin{array}{c}124 \\
-256733\end{array}$ & $18.10 \%$ \\
\hline 2014 & 2104 & 632 & $\begin{array}{c}119 \\
-250733\end{array}$ & $2(4631)$ & $\begin{array}{c}121 \\
-255364\end{array}$ & $17.60 \%$ \\
\hline 2015 & 2127 & 656 & $\begin{array}{c}106 \\
-227724\end{array}$ & $9(18865)$ & $\begin{array}{c}115 \\
-246589\end{array}$ & $17.30 \%$ \\
\hline 2016 & 2178 & NA & $\begin{array}{c}102 \\
-260572\end{array}$ & $12(37174)$ & $\begin{array}{c}120 \\
-297746\end{array}$ & $16.90 \%$ \\
\hline 2017 & 2215 & NA & $\begin{array}{c}110 \\
-244074\end{array}$ & 30 (66967) & $\begin{array}{c}140 \\
-311041\end{array}$ & $17.00 \%$ \\
\hline 2018 & 2251 & 917 & $\begin{array}{c}136 \\
-305626\end{array}$ & $\begin{array}{c}51 \\
-114808 \\
\end{array}$ & $\begin{array}{c}187 \\
-420434 \\
\end{array}$ & $19.50 \%$ \\
\hline 2019 & 2287 & 866 & $\begin{array}{c}143 \\
-326305\end{array}$ & $\begin{array}{c}70 \\
-160080\end{array}$ & $\begin{array}{c}213 \\
-486385\end{array}$ & $20.20 \%$ \\
\hline 2020 & 2324 & 482 & $\begin{array}{c}104 \\
-242323\end{array}$ & $\begin{array}{c}53 \\
-124318\end{array}$ & $\begin{array}{c}158 \\
-366641\end{array}$ & $20.30 \%$ \\
\hline
\end{tabular}


Table 2: Physical infrastructure of NTEP in UP.

\begin{tabular}{|c|c|}
\hline Total population & $\mathbf{2 3 . 2 4}$ cr \\
\hline Urban population & $5.1 \mathrm{cr}(22.2 \%)$ \\
\hline Districts & 75 \\
\hline TUs & 993 \\
\hline DMCs & 2063 \\
\hline IRL & 2 \\
\hline STDC & 1 \\
\hline RTPMU & 5 \\
\hline
\end{tabular}

NTEP was implemented in Gujarat state in 1998 and it is one of the better performing states as far as control of TB is concerned [17]. There are other states in India who have better indicators, but they are small states. Gujarat is demographically comparable to UP state [18], and its key indicators of case finding are much higher compared to UP [2]. In the year 2015, which is considered as benchmark for TB free certification [2] the presumptive TB examination rate in Gujarat was 884 per lakh population which increased to 1164 in 2020 along with increase in CNR from 128 to 173 per lakh population in 2020 while Presumptive TB examination of UP was 624 per lakh population in 2015 which decrease to 482 in 2020 along with increase in CNR from 115 to 158 per lakh population which suggests that despite a decrease efforts for case detection, case notification has increase as compared to 2015 $[2,19]$. Hence, more of vigorous active case finding strategies are required.

UP is one of the five states besides Maharashtra, Madhya Pradesh, Gujarat and Rajasthan that contributes half of the total notified TB cases in India [2]. The annual TB case notification is increase during the last 10 years. It is evident from, there is a doubling observed in case notification rate from 2011 to 2019 with a fall in 2020 probably due to COVID-19 pandemic situation in the country. Apart from Ladakh, Lakshadweep, Mizoram and Sikkim, all the states and UTs in India presented a decrease in TB notification rates in the March-April 2020 [2]. The same was observed in UP with the first half of 2020 witnessing a $50 \%$ fall in TB notification due to vast hampering of the nationwide health system and restriction of movement due to lockdown situation [2]. But the state took vigorous steps like Active case finding and TB-COVID bi- directional screening which helped in increasing the TB notification by $26 \%$ in the last half of 2020 [2]. A well-planned screening for active TB among the high-risk groups is an established effective strategy to improve early case detection [2]. Active case finding activities were being implemented in NTEP since 2017 [20,21]. UP conducted ACF activities with 10121 patients diagnosed of TB among 43 million population mapped in 20202 and 14000 TB patients diagnosed among 56 million population mapped in 2019 [22] with the help of mobile TB diagnostic van enabling early TB diagnosis especially in hard-to-reach areas.

One of the major hindrances in TB detection is poorly established specimen collection and transportation systems in India [23]. Even though UP piloted the use of public postal service for sample transportation in 2019 when nationwide efforts were being made to link the sputum transport with India postal services28, it still needs to strengthen and monitor the engagement of public postal service for sample transportation. Figure 1 reveals that private TB case notification have increased over the past 10 years. Much of this increase in notification is credited to the directly transferred benefit (DBT) scheme of NTEP2 and the fact that the TB was declared as a notifiable disease in May 2012 [24]. UP has shown a considerable achievement in private case notification rate over a period of last 7 years since private sector started notifying TB cases.

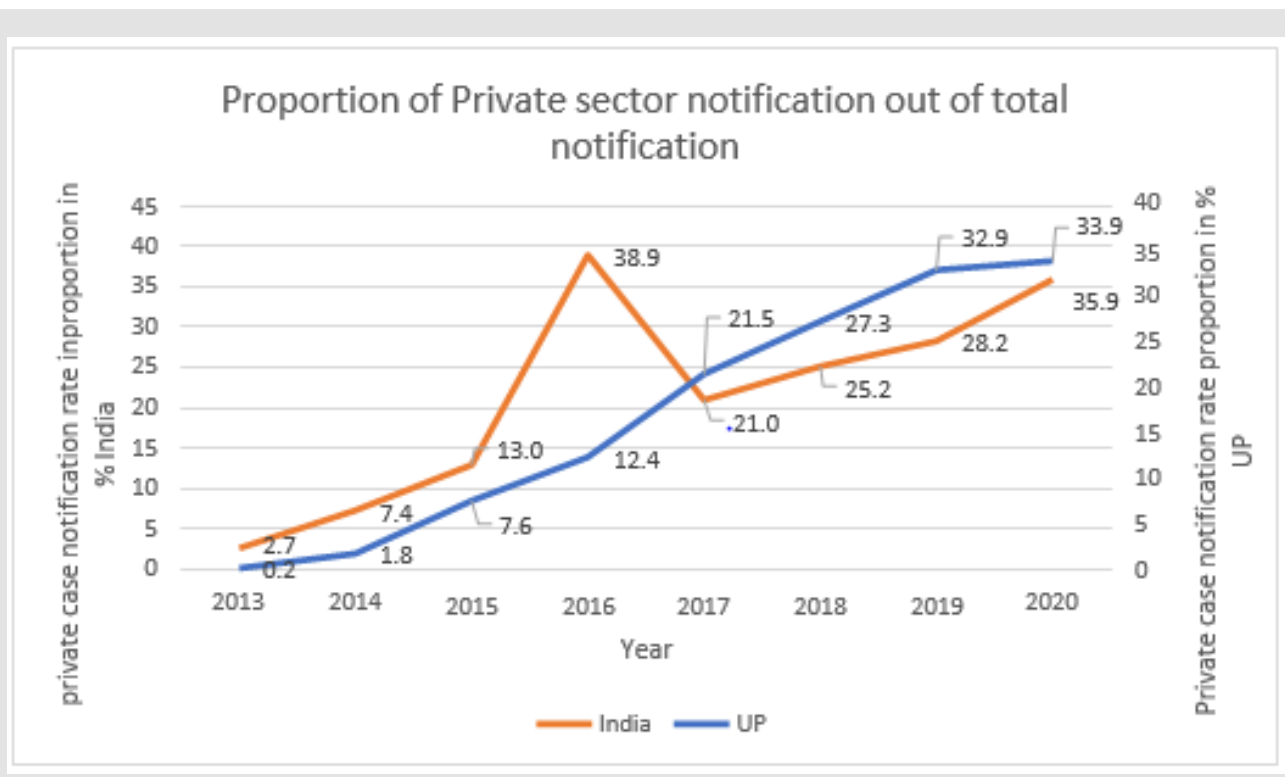

Figure 1: Comparison of Private Sector notification of NTEP-UP and India. 


\section{Multi-Drug Resistant TB}

Drug resistant TB is one of the major impediments to achieving the National strategic plan (NSP) goal of ending TB in India [10]. India bears $27 \%$ of the global burden of multi-drug resistant $\mathrm{TB}$ (MDR-TB) cases [2] An estimated 1,24,000 people developed MDRTB in India in 2019, i.e., 9.1 cases per one lakh population [2]. The first national anti-TB drug resistance survey reported $28 \%$ of TB patients resistant to any drugs and 6.2\% having MDR TB. India is one of the countries with highest burden of MDR-TB in the world and UP is the one state which contributes to the maximum load of MDR-TB in India [2]. UP has introduced Programmatic management of drug resistant TB services in all 75 districts in 2013 [12]. It has 23 nodal DR-TB centers operationalized by airborne infection control measures [2]. UP contributes to $25 \%$ of total DRTB case notification of India [2] (Figure 2) In 2020, Universal drug susceptibility testing. was offered to $60 \%$ of notified TB patients in. DR-TB Case notification rate in UP is 5.3 per lakh population in 2020 Thus, more intensive efforts are required to offered UDST to all the eligible DR-TB patients [2]. (Figure 2) reveals an increasing trend of DR-TB cases in the last 10 years with a fall observed in the year 2020 due to COVID-19 pandemic when the overall case notification was reduced.

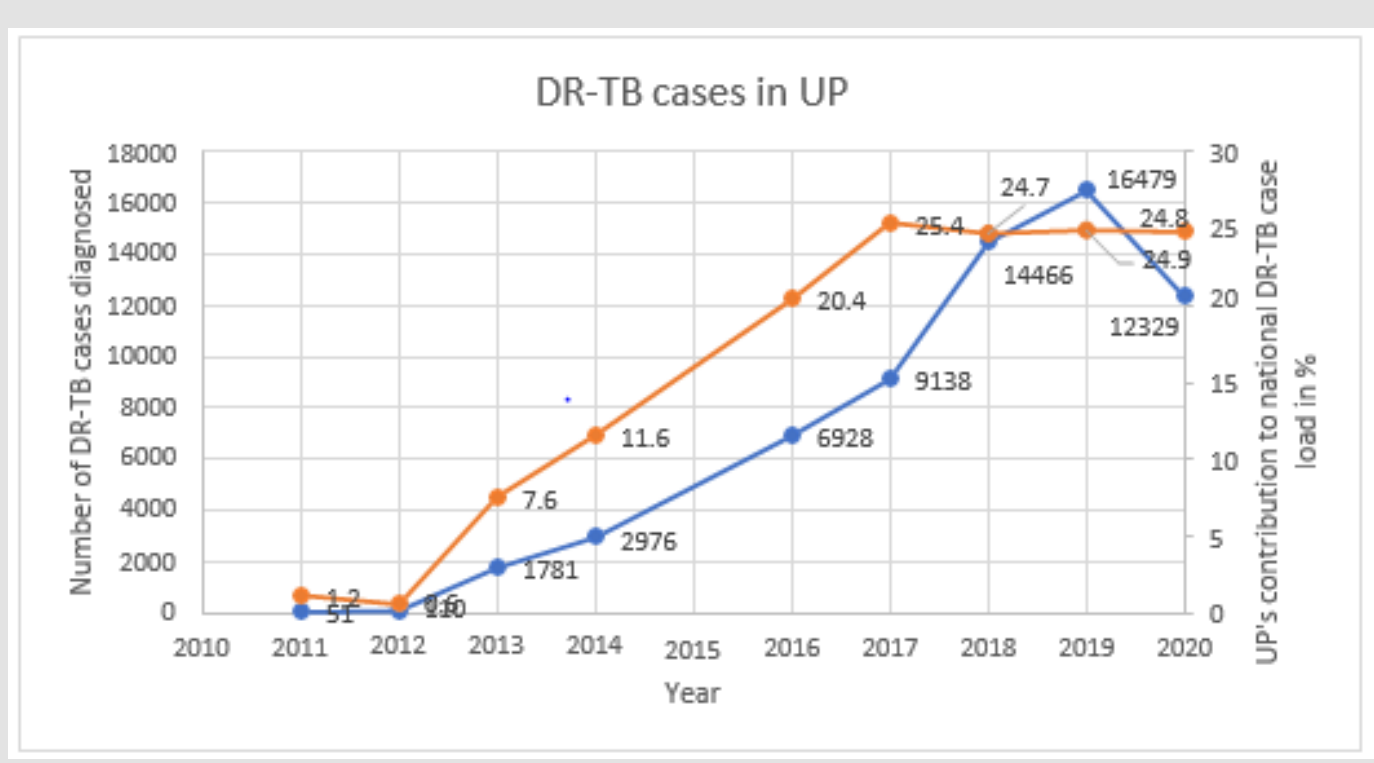

Figure 2: Trend of Drug resistant TB in NTEP-UP.

\section{TB-HIV}

Human Immunodeficiency Virus (HIV) is a risk factor for TB which not only increases the risk of reactivating latent TB infection but also increases the risk of rapid TB progression soon after the TB infection or reinfection. TB in people living with HIV is very difficult to diagnose and treat owing to challenges related to comorbidity, pill burden, co-toxicity and drug interactions [25]. India accounts for the highest burden of TB-HIV co-infected cases [2] India initiated provider-initiated testing and counselling among presumptive TB cases for early detection of HIV [2]. UP is a low HIV prevalence state. Out of the total TB-HIV burden, UP contributes about $6.95 \%$ of the total TB-HIV burden in India.2 In 2020, there were 2356 TB HIV co-infected patients diagnosed with HIV among those tested. Guidelines on prevention and management of TB in people living with HIV at ART centers recommended all TB-HIV coinfected patients should receive cotrimoxazole prophylactic therapy to prevent development of other common opportunistic infections [26].
In $2020,94 \%$ of the total diagnosed HIV patients with TB were initiated on CPT whereas $92 \%$ were initiated on ART.2 UP reported high coverage of HIV testing among TB patients notified in 2019 especially in the public sector (85\%) [27]. In UP, State TBHIV coordination committee (STCC) and State Technical Working Group (STWG) monitors key policy related to TB-HIV collaborative activities. District TB officers were given the charge of District HIV Nodal officers in 2008 making them the focal point for both TB and HIV related activities and better implementation of policy decisions [12,27-30].

\section{Regional TB Programme Management Units: An Innova- tive Idea}

Over the years India has been trying to initiate and implement new ideas of controlling and eliminating Tuberculosis from the country. Thus, in line with the Country's view the State of Uttar Pradesh is working on the same path and has taken new initiatives to achieve the goals. Though the complete implementation of 
NTEP in the state was in the year 2006, in year 2014 an innovation through National Health Mission was conceived which lead to the establishment of four Regional TB Program Management Unit (RTPMU) at Agra, Bareilly, Lucknow and Varanasi. Recently, fifth RTPMU was inaugurated at Gorakhpur, UP [12]. Because of the fact that UP being a large state with 75 districts thus NTEP-UP has always faced a challenge of intensive monitoring, supervision and evaluation of all the districts in the programme from one State unit which is the State TB Cell at Lucknow [12]. Thus, a felt need for decentralization of the State Program Management, Supervision \& Monitoring from State Head Quarter to the Regional levels units was seen.

The vision of RTPMU is handholding of districts with supportive supervision Each RTPMU is working as a satellite unit of both STC (State TB Cell) at Lucknow \& STDC (States NTEP training and quality assurance establishment located) at Agra and are performing their key roles while supporting the districts linked to them which has led to a more effective Administration, Supervision, Monitoring, Training, External Quality Assurance, Reviews, Logistic management etc. [12]. Functions of RTPMU are to share the responsibilities of STC and STDC to effectively supervise, monitor and provide training as well as feedback to their linked districts for TB control. RTPMU is managed by a regional TB program management officer (RTPMO), 2 Deputy RTPMO, Consultant, Data entry operator and office assistant [12]. Thus, since the establishment of the five RTPMU's state has achieved a noteworthy improvement in the key indicators and had shown the National Program Managers at Government of India \& WHO that the preconceived notion of UP being a nonperforming state is gradually negated [31].

\section{Conclusion}

UP contributes to the maximum case load of drug sensitive TB (20\%) and DR-TB (25\%) in India. Being a vast and populous state with 75 districts, it has a mammoth task lying ahead to eliminate TB by 2025. The usual notion of UP being a nonperforming state is gradually changing. This is reflected in the efforts put by the NTEPUP and the achievements attained so far be it in terms of active case finding of TB cases, increase in private sector notification, using Indian postal service to improved sputum specimen transportation, mobile medical van facilities in hard-to-reach area and better monitoring of the program in the state. The RTPMUs established shows the decentralization efforts of the state linking each district to a particular RTPMU and increasing the accountability for TB. And these efforts are on-going, be it the recent establishment of RTPMU Gorakhpur or the Chief Minister of UP urging ministers and lawmakers to adopt one TB patient each to achieve the target of making UP free of TB which shows the hardcore commitment of the state to eliminate TB. Private sector notification and the proportion of UDST offered to TB patients needs to be further increased in UP. A more focused approach is required for each and every component of the TB program in UP. as a slight change in TB situation in UP will have a huge impact on the nation's TB status and thus will pave way for eliminating TB from India by 2025.

\section{References}

1. (2021) World Health Organization. Global Tuberculosis Report.

2. (2021) National TB Elimination Program. India TB Report 2021 Annual Status Report.

3. Narain JP (2016) Public health challenges in India Seizing the opportunities.pdf. IJCM 41(2): 85-88.

4. Patil JS (2015) Current Treatment of Tuberculosis. J Pharmacovigil 3(4): $1000 \mathrm{e} 143$.

5. Barberis I, Bragazzi NL, Galluzzo L, Martini M (2017) The history of tuberculosis: from the first historical records to the isolation of Koch's bacillus. J Prev Med Hyg 58(1): E9-E12.

6. Gupta N (2016) Tuberculosis: Current Scenario in India. Sci India.

7. Gupta D (2018) Administrative challenges in the implementation of RNTCP. Indian J Tuberc 65: 187-189.

8. Sachdeva KS, Malik Parmar, Raghuram Rao, Sandeep Chauhan, Vaibhav Shah, et al. (2020) Paradigm shift in efforts to end TB by 2025. Indian J Tuberc 67(4S): S48-S60.

9. Vijay S, Kumar P, Chauhan LS The History of Tuberculosis Control in India: Glimpses through Decades. In: Tuberculosis Control in India, p. $15-22$

10. (2017) Central TB Division, Directorate General of Health Services, Welfare $\mathrm{M}$ of $\mathrm{H}$ with F. National Strategic Plan for Tuberculosis Elimination 2017-2025

11. Arora VK, Chopra KK (2019) Journey of tuberculosis control in India. Indian J Tuberc 66(1): 178-183.

12. (2015) UP ST cell. Annual Status Report 2015 Uttar Pradesh, India.

13. (2008-2021) State N health mission UP. Uttar Pradesh State Program Implementation Plan.

14. (2013) NRHM U. Demographic Profile \& Health Care Delivery System.

15. Baliyan S kumar (2016) Demographic Changes and Growth of Population in Uttar Pradesh. Trends and Status. International Journal of Social Sciences and Management 3(4): 228-238.

16. (2016) Revised National Tuberculosis Control Program. Technical and operational guidelines for TB control in India.

17. Ramachandran R, Nalini S, Chandrasekar V, Sanghvi AS, Wares F, et al. (2009) Surveillance of drug-resistant tuberculosis in the state of Gujarat , India. Union 13(9): 1154-1160.

18. (2011) C. State Census 2011.

19. (2015) Revised National Tuberculosis Control Program 2015. TB India 2015 Annual Status Report.

20. (2018) Revised National Tuberculosis Control Program2015. India TB report 2018 Annual status report.

21. (2019) Revised National Tuberculosis Control Program. India TB Report 2019 Annual Status Report.

22. (2020) Revised National Tuberculosis Control Program. INDIA TB REPORT 2020 Annual Status Report.

23. (2019) Revised National Tuberculosis Control Program. Report of the Joint Monitoring Mission. 
24. (2012) RNTCP. Mandatory TB Notification Gazette for Private Practitioners, Chemists and Public Health Staff Frequently Asked Questions (FAQs).

25. (2015) Central TB division N. Integrated Training Module for HIV / TB Collaborative Activities.

26. (2016) NACO. Guidelines on Prevention and Management of TB in PLHIV at ART Centers.

27. (2012) Revised National Tuberculosis Control Program 2015. TB India 2012 Annual Status Report.

\section{ISSN: 2574-1241}

DOI: $10.26717 /$ BJSTR.2021.39.006246

Arohi Chauhan. Biomed J Sci \& Tech Res

(C) This work is licensed under Creative

Submission Link: https://biomedres.us/submit-manuscript.php
28. (2013) Revised National Tuberculosis Control Program 2015. TB India 2013 Annual Status Report

29. (2014) Revised. TB India 2014 Annual Status Report.

30. Revised National Tuberculosis Control Program. TB India 2016 Annual Status Report.

31. (2017) Revised National Tuberculosis Control Program. TB India 2017 annual status report. RNTCP Annu Status Rep, pp. 1-173.

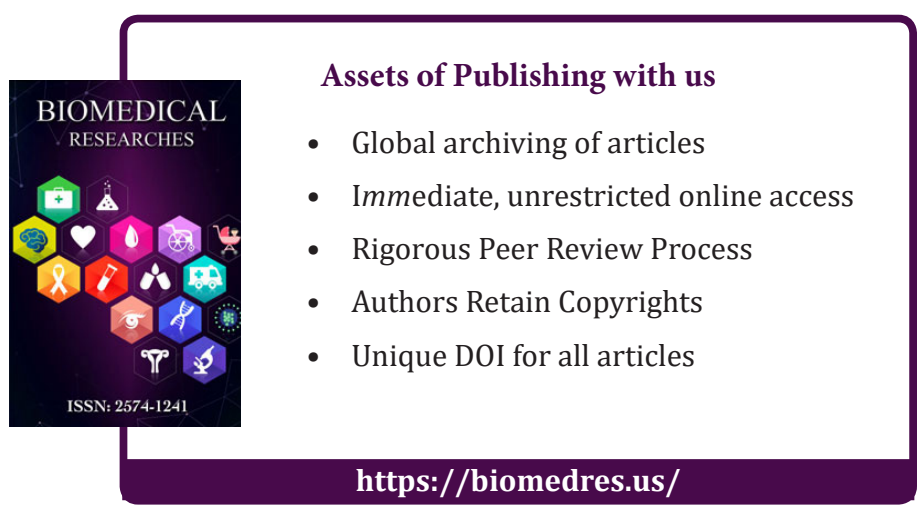

